\title{
Prevalence and Associated Risk Factors to Lice Infestation in Sheep of Arsi High Land, Oromiya Regional State, Ethiopia
}

\author{
Eyob Eticha ${ }^{1^{*}}$, Diriba Lemma1 ${ }^{1}$ Birhanu Abera ${ }^{1}$ and Hani Selemon ${ }^{2}$
}

${ }^{1}$ Asella Regional Veterinary Laboratory, PO Box 212, Asella, Ethiopia

${ }^{2}$ Arsi University School of Agricultural and Environmental Science, Asella, Ethiopia

\begin{abstract}
This study was done from November 2011 to March 2012. A total of 384 sheep from Tiyo District of Arsi Zone, around High land area of Asella were selected for the study. A cross sectional study was conducted to determine the prevalence of lice in sheep and to identify major species of lice in the study area. The densities of lice were determined through counting after parting of the fleece/wool at five (5) points on a length of $10 \mathrm{~cm}$ in different regions of the body (neck, shoulder, back, rump and flank) on both sides. The overall prevalence of lice infestation was found $53.9 \%(n=384)$. From this Damalina ovis takes the highest prevalence in each variable (sex, age, body condition and month) whereas Linognathus ovillus had lower prevalence in each variable. The prevalence of lice for female and male was $53.26 \%$ and $56.4 \%$, respectively. Adult and young infestation rate of lice was $51.52 \%$ and $57.5 \%$, respectively. Prevalence of lice infestation in good, medium and poor body condition was $36.8 \%(64), 62.7 \%$ (94) and $81.7 \%$ (49), respectively. The prevalence of lice in November was $74.44 \%$ (94), in January $32.8 \%(42)$ and in February $55.5 \%(71)$. There is statistically significant difference in the occurrence of lice infestation between body condition scores and months $(p<0.05)$ but there is no statistically significant difference between age and sex $(p>0.05)$. These result shows that lice infestation has a great effect on the skin quality and on the production of meat and milk. From this result it can be concluded that occurrence of lice depends on body condition and climatic factor. Therefore, owners should practice good management system by keeping the hygiene of animal and by avoid mixing of healthy animals from diseased once with the use effective acarcide control.
\end{abstract}

Keywords: Asella; Lice; Prevalence; Sheep

\section{Introduction}

In Ethiopia, small ruminants comprise large proportion of livestock resources, constitute about $30 \%$ of the total livestock population of the country and are among important contributors to food production in Ethiopia, providing $35 \%$ of meat consumption and $14 \%$ of milk consumption [1]. And the country is an ideal case for studying livestock diversity in the context of developing regions. It is route of sheep migration from Asia into Africa, has large population [2] and diverse traditional sheep breeds spread across diverse ecology, communities, and production system. At the national level, sheep/goat account for about $90 \%$ of the live animal/meat and $92 \%$ of skin and hide export trade value [3]. At the farm level sheep contribute as much as $22-63 \%$ to the net cash income derived from livestock production in the croplivestock production system [4].

Lice are among the major disease of sheep and cause serious economic loss to farmers through mortality, decreased production and reproduction, down grading and rejection of skins which also affect the tanning industries. According to tanneries report, skin diseases due to external parasites cause 35\% sheep skin rejection [5], among highly prevalent and pathogenic ectoparasites of sheep. Both biting and sucking lice affect small ruminants. The important species of lice found in sheep and goats are the genus Damalina and Linognathus and the important species in sheep being $L$. ovillus (sucking face louse), L. aficanus, L. spedalis (sucking foot louse) and Bovicola ovis (biting louse). In goats L. stenopsis (sucking blue louse), L. africanus, B. caprae (biting louse), B. alimbata and B. crassiceps are reported [6].

All species cause irritation of the skin, stimulate scratching, rubbing, and licking leading to restlessness, these have great effect on sheep production and skin quality [5]. Accordingly, the enormous economic losses induced by Lice in sheep necessitate detailed investigation on their incidence in order to organize efforts to at least minimize these losses. This study is therefore aimed for assessing the prevalence of lice and determining the magnitude of lice infestation in relation to associated risk factors.

\section{Materials and Methods}

\section{Study area}

The present study was conducted from November 2011 to March 2012 in Tiyo district of Arsi Zone, around highland area of Asella, capital town of Arsi zone, which is located at $175 \mathrm{~km}$ southeast of Addis Ababa, and the altitude and annual rainfall of the area ranges from 502-4130 meters above sea level and 200-400 $\mathrm{mm}$ with mean annual temperature of $22.5^{\circ} \mathrm{C}$, respectively. It is one of the highly-populated areas in Ethiopia with estimated human population of 2,521,349 and livestock population of cattle-82,190; sheep-51,292; goat-8, 11,479; poultry- 5, 62,915; equine- 22,055 [7].

\section{Study design and sampling strategies}

A cross sectional study was conducted to determine the prevalence of lice in indigenous sheep in the study areas. With the assumption of possible prevalence rate of the disease $50 \%$, absolute desired precision

*Corresponding author: Fanos Tadesse Woldemariyam, College of Veterinary Medicine and Agriculture, Addis Ababa University, Addis Ababa, Ethiopia, Tel: +251912828253; E-mail: fanos.tadesse@aau.edu.et

Received January 17, 2017; Accepted February 09, 2017; Published February 11,2017

Citation: Eticha E, Lemma D, Abera B, Selemon H (2017) Prevalence and Associated Risk Factors to Lice Infestation in Sheep of Arsi High Land, Oromiya Regional State, Ethiopia. J Vet Sci Technol 8: 425. doi: 10.4172/2157-7579.1000425

Copyright: $\odot 2017$ Eticha E, et al. This is an open-access article distributed under the terms of the Creative Commons Attribution License, which permits unrestricted use, distribution, and reproduction in any medium, provided the original author and source are credited. 
of $5 \%$ and confidence level of $95 \%$ was considered for estimation prevalence in the simple random sampling according to Thrusfield, [8] the total sample size was 384 sheep.

\section{Study population}

The present study involved sheep kept under extensive (mixedcrop livestock production) production system in selected peasant associations of Tiyo district. A total 384 sheep was randomly selected from 19,453 sheep population in the district. The sampling was made by 3 rounds in different months of the study period.

\section{Clinical examinations}

The animals were randomly selected and clinically examined for presence of the ectoparasites. Prior to clinical examination, the sex, ages, body condition scores of the selected animals were recorded. The different age groups such as young and adult have been selected for the present study and the age group was done as per standard method of Hamito [9]. Body condition score of the animals will be considered as poor, medium, and good by modifying the system described by Johns [10] for sheep. The clinical examination was performed by multiple fleeces parting in the direction opposite that in which hair or wool normally rests and visual inspection and palpation of the skin for parasites on neck, shoulder, wither, flank and ramps are sites of concern. In each of the mentioned body parts both on the either sides /left and right/ a place $10 \mathrm{~cm}$ long is parted for the presence of lice and if found in all or one of the $10 \mathrm{~cm}$ long place. Those sheep found infested by parasites was considered positive. The type of parasites was identified on the basis of their morphological structure as described in Wall and Shearer [11].

\section{Specimen collection and examination}

Those detected lice that are unidentified during clinical examination was collected by forceps/hand picking, with hairs from their attachment site, put into a clean separate container(universal bottles), labeled and kept preserved with $70 \%$ ethyl alcohol before transportation to Asella regional veterinary laboratory for detailed laboratory examination as described by Urquhart et al. [12]. Then the collected ectoparasites was examined by stereomicroscope and identification was performed according to the identification key given by wall and shearer [11].

\section{Data management and analysis}

The data was subjected for statistical analysis by entry in to Microsoft Excel spread sheet and descriptive statistics like prevalence and analytical statistics such as chi- square $\left(\chi^{2}\right)$ was conducted by using SPSS 17.0 for determining the significance of association between age groups, sex, body condition scores, and month with lice infestation. For the purpose of this study, $95 \%$ confidence level and $P<0.05$ was used for significance.

\section{Results}

\section{Overall prevalence of lice}

Out of the total sheep population examined for lice infestation, $53.9 \%$ (207) sheep were infested with lice. The major species of lice were D. ovis and L. ovillus species, from this the most prevalent species was $D$. ovis with an overall prevalence of $86.9 \%$ (180) while L. ovillus species was only $1.9 \%$ (4) and mixed lice infestation was $11.6 \%(23)$. The commonest site of lice attachment was the skin of neck, shoulder, flank and rump.

\section{Prevalence of lice in sheep by different age groups}

Out of the total population of sheep examined for lice infestation $60.2 \%$ (231) sheep was adult and 39.8\% (153) was young. The overall prevalence of lice infestation in adult was $51.52 \%$ (119) where as in young it was $57.5 \%$ (88) of this the most prevalent lice species were $D$. ovis with the prevalence of $89.1 \%(106)$, where as L. ovillus species have 0 prevalence and mixed lice infestation was $10.9 \%(13)$ in adult and in case of young (lamb) D. ovis $84.09 \%$ (74), L. ovillus species $4.54 \%(4)$ and mixed lice infestation $11.36 \%(10)$ (Table 1). In both age groups there is no statistically significant difference $(p=0.248)$

\section{Prevalence of lice in sheep by different sex group}

Out of the total population of sheep examined for lice infestation $79.7 \%$ (306) sheep were female and $20.3 \%$ (78) are male. The overall prevalence of lice in female is $53.26 \%$ (163) and in male are $56.4 \%$ (44) The most prevalent species is D. ovis with the prevalence of $87.12 \%$ (142), whereas L. ovillus $1.23 \%$ (2) and mixed $11.66 \%$ (19) in female sheep. In male sheep the prevalence of D. ovis was $100 \%$ (44), L. ovillus $9.1 \%$ (4) and mixed infection is $9.1 \%$ (4) (Table 2). In both sex groups there is no statistically significant difference $(p=0.619)$.

\section{Prevalence of lice infestation in sheep by different body condition}

From the total population of sheep examined for lice infestation $45.3 \%$ (174) sheep have good body condition, 39.1\% (150) sheep have medium body condition and $15.6 \%$ (60) sheep have poor body condition. The overall prevalence lice infestation of good, medium and poor body conditions was $36.8 \%$ (64), 62.7\% (94) and $81.7 \%$ (49), respectively. The most prevalent species was $D$. ovis with the prevalence of $90.6 \%$ (58), L. ovillus 3.13\% (2) and mixed lice infestation $6.25 \%$ (4) in good body conditioned animal. In medium body condition animal the prevalence of D. ovis was $84.04 \%$ (79), L. ovillus $1.064 \%$ (1) and mixed lice infestation $14.89 \%$ (14). In poor body condition prevalence of D. ovis was $87.76 \%$ (43), L. ovillus $2.04 \%$ (1) and mixed lice infestation $10.2 \%$ (5) (Table 3 ). There is statistically significant difference in the occurrence of lice infestation between body condition sores $(p=0.000)$.

\section{Prevalence of lice infestation in sheep by month wise}

Out of the total population of sheep examined for lice infestation equal numbers of sheep were taken in each month (i.e., 33.3\% (128), in November, 33.3\% (128) in January and 33.3\% (128) in February). Out of this the overall prevalence of lice in November was $73.44 \%$ (94), in January $32.8 \%$ (42) and in February 55.5\% (71). Out of this prevalence of D. ovis was found $85(90.42 \%)$, L. ovillus 0 prevalence and mixed lice infestation $9.6 \%$ (9) in November. In January the prevalence of $D$. ovis was $83.33 \%$ (35), L. ovillus 0 prevalence and mixed lice infestation $16.66 \%$ (7). In February prevalence of D. ovis was $84.5 \%$ (60), L. ovillus $4.22 \%$ (3) and $15.5 \%$ (11) and mixed lice infestation 9.86\% (7) (Table 4). There is statistically significant difference in between the three months $(\mathrm{p}=0.000)$.

\begin{tabular}{|c|c|c|}
\hline Lice & Adult & Young \\
\hline D. ovis & $89.1 \%(106)$ & $84.09 \%(74)$ \\
\hline L. ovillus & $0 \%(0)$ & $4.54 \%(4)$ \\
\hline Mixed lice & $10.9 \%(13)$ & $11.36 \%(10)$ \\
\hline Overall lice & $51.52 \%(119)$ & $57.5 \%(88)$ \\
\hline
\end{tabular}

For Total infestation Chi square $(\mathrm{df}=1)=1.334, P=0.248$

Table 1: Prevalence of lice in sheep by age wise. 
Citation: Eticha E, Lemma D, Abera B, Selemon H (2017) Prevalence and Associated Risk Factors to Lice Infestation in Sheep of Arsi High Land, Oromiya Regional State, Ethiopia. J Vet Sci Technol 8: 425. doi: 10.4172/2157-7579.1000425

Page 3 of 4

\section{Prevalence of lice in sheep by severity}

Out of the total population of sheep infected with lice $41.06 \%$ (85) sheep were severely infected, 101(48.79\%) sheep with moderate infection and $10.14 \%(21)$ were with slight infestation. The most prevalent species was D. ovis with the prevalence of $97.65 \%$ (83), $79.2 \%(80)$ and $85.71 \%(18)$ in severe, moderate and slight infestation respectively. While for $L$. ovillus $1 \%$ (1) was slight infestation and $14.29 \%$ (3) was moderate infestation. In mixed lice infestation $2.35 \%$ (2) was for severe infestation and $20.79 \%$ (21) for moderate infestation (Table 5).

\section{Discussion}

The high prevalence of lice was $53.9 \%$, recorded in the study, which is suggestive of the importance of the parasite in sheep population of the study area. Poor management and poor level of awareness of sheep owners on the effect of ectoparasites particularly lice infestation are believed to have contributed to wide spread occurrence of the parasites. D. ovisis the most prevalent lice species recorded with a prevalence of $86.9 \%$, from the 207 sheep infected with lice infestation where as L. ovillus species and mixed lice infestation were $1.9 \%$ and $11.6 \%$ respectively.

The overall prevalence obtained in this study is higher than observations made in North western Amhara Region [13] which is $30.9 \%$ for D. ovis, by Tadesse et al. [14] $22.28 \%$ for B. ovis in around Kombolcha and by Sertse [15] 25.7\% in Amhara region. But the present findings indicates lower prevalence than prevalence of $63.5 \%$ as reported in Amhara National Regional State [16] and by Yacob et

\begin{tabular}{|c|c|c|}
\hline Lice & Female & Male \\
\hline D. ovis & $87.12 \%(142)$ & $100 \%(44)$ \\
\hline L. ovillus & $1.23 \%(2)$ & $9.1 \%(4)$ \\
\hline Mixed lice & $19(11.66 \%)$ & $9.1 \%(4)$ \\
\hline Over all lice & $53.26 \%(163)$ & $56.4 \%(44)$ \\
\hline
\end{tabular}

For Total infestation Chi square $(\mathrm{df}=1)=0.247, P=0.619$

Table 2: Prevalence of lice in sheep by sex wise

\begin{tabular}{|c|c|c|c|}
\hline Lice & Poor & Medium & Good \\
\hline L. ovillus & $2.04 \%(1)$ & $1.064 \%(1)$ & $90.6 \%(58)$ \\
\hline D. ovis & $43(87.76 \%)$ & $84.04 \%(79)$ & $36.8 \%(64)$ \\
\hline Mixed lice & $10.2 \%(5)$ & $14.89 \%(14)$. & $3.13 \%(2)$ \\
\hline Overall lice & $81.67 \%(49)$ & $62.7 \%(94)$ & $6.25 \%(4)$ \\
\hline
\end{tabular}

For Total infestation Chi square $(\mathrm{df}=6)=43.778, P=0.000$

Table 3: Prevalence of lice in body condition.

\begin{tabular}{|c|c|c|c|}
\hline Lice & November & January & February \\
\hline D. ovis & $90.42 \%(85)$ & $83.33 \%(35)$ & $84.5 \%(60)$ \\
\hline L. ovillus & $0 \%$ & $0 \%$ & $4.22 \%(3)$ \\
\hline Mixed lice & $9.6 \%(9)$ & $16.66 \%(7)$ & $15.5 \%(11)$ \\
\hline Overall lice & $73.44 \%(94)$ & $32.8 \%(42)$ & $55.5 \%(71)$ \\
\hline
\end{tabular}

For Total infestation Chi square $(\mathrm{df}=2) 42.698, P=0.000$

Table 4: Prevalence of lice by month wise.

\begin{tabular}{|c|c|c|c|}
\hline Lice & Severe & Moderate & Slight \\
\hline D. ovis & $97.65 \%(83)$ & $79.2 \%(80)$ & $85.71 \%(18)$ \\
\hline L. ovillus & $0 \%$ & $3(14.29 \%)$ & $1 \%(1)$ \\
\hline Mixed lice & $2.35 \%(2)$ & $20.79 \%(21)$ & $0 \%$ \\
\hline Overall lice & $41.06 \%(85)$ & $48.79 \%(101)$ & $10.14 \%(21)$ \\
\hline & Table 5: Prevalence of Lice by Severity.
\end{tabular}

al. [17] in Southern Ethiopia, Sodo, and in the Zone of this study area, Arsi, which was $75.5 \%$. Such difference in prevalence with the above observations may arise from differences in agro climate, management, health care of animal and the sensitivity of the diagnostic method used to reveal ectoparasites. Similarly, lice infestation was greater in winter and spring similar to the findings of Colwel et al. [18].

In addition to skin damage, lice infestation also has a significant effect on production and productivity of animals because the presence of lice interferes with nutrition of animal. Due to itching and scratching the animal spend more time by grooming on fixed objects rather than taking feed which result in decreased body Condition. Body condition has also contribution for the occurrence of lice infestation because there is also evidence that immune response may be involved in regulating louse numbers and may underlie differences amongst sheep in susceptibility to lice $[19,20]$. Impaired immune response may explain the greater susceptibility to lice of animals in poor condition or under stress.

In the present study sex and age are not statistically significant in the occurrence of lice infestation but in male animal the prevalence of lice is slightly higher than female animal and in young the prevalence of lice infestation is higher than in adults this is because the lambs doesn't mixed with ewes therefore transmission from ewe to lamb doesn't occur.

The other factor for the occurrence of lice is climatic condition. In this study the occurrence of lice is higher in November than February and January, which shows infestation of lice is high in cooler time. According to Wilkinson et al. [21]; Niven and Pritchard [22] lice infestation is very high in spring time in European countries where the temperature is low during that time.

Considering the importance of skin and hides as a main source of foreign currency to the country, the prevailing ecto parasites mainly in different sheep reared in Arsi zone requires attention in order to minimize the spread of infestation and increase income earnings of farmers and small scale holders whose livelihood is dependent on their animals.

\section{Conclusion}

Lice infestation is among the major causes of sheep production constraints and quality deteriorations of exported skin in Ethiopia. Lice are easily overlooked because of their small size but they have the capacity to multiply very fast before being discovered. In this study the overall prevalence of lice infestation was very high (86.9\%), this can be resulting in high economic losses through decreased production of meat and milk due to interference with nutrition and skin damages. Lice have a significant effect on body condition. Whereas sex and age of the host animals were not determinant factors for the prevalence variation. Therefore, based on the above points the following recommendations are forwarded: The effect of lice on production, productivity and skin quality is not appreciated by farmers. Therefore farmers should have enough awareness and effective extension programs that raise public awareness on effect of lice, reducing the prevalence of Lice mainly relies on treatment of affected animals with appropriate acaricides and improving the management system and detailed study on economic losses associated with lice infestation and investigation of other causes of skin downgrading and rejection should be conducted.

\section{Acknowledgements}

Authors are grateful for the technical and material support of the staffs of Asella regional veterinary laboratory. 
Citation: Eticha E, Lemma D, Abera B, Selemon H (2017) Prevalence and Associated Risk Factors to Lice Infestation in Sheep of Arsi High Land, Oromiya Regional State, Ethiopia. J Vet Sci Technol 8: 425. doi: 10.4172/2157-7579.1000425

\section{References}

1. Asfaw B (1998) The Tanning Industry. Proceedings of control of sheep and goat skin disease to improve quality of hides and skin, Addis Ababa, Ethiopia.

2. CSA (2006) Ethiopian Agricultural Sample Enumeration. Statistical report on Livestock and Farm Implements, Addis Ababa, Ethiopia.

3. Gizaw G (2008) Sheep resources of Ethiopia: Genetic Diversity and Breeding Strategy. PhD Thesis, Wageningen University, The Netherlands, pp: 2-145.

4. Zelalem A, Feltcher IC (1993) Small Ruminant Productivity in the central Ethiopian Mixed Farming System. In: Processing of the Fourth National livestock Improvement Conference, Addis Ababa, Ethiopia.

5. Bayou K (1998) Overview of sheep and goat skin diseases, treatment trial for improved quality of hides and skins (phase II). Addis Ababa, Ethiopia, pp: 13-20.

6. Radostits OM, Blood DC, Gay CC (1994) Veterinary Medicine. Text Book of Cattle, Sheep, Pigs, Goats and Horses. 8th edn, Bailliere Tindall, UK, pp: 1280-1308.

7. Deselegn TB, Gangwar SK (2011) Seroprevalence study of bovine brucellosis in Assela government dairy farm of Oromia Regional State, Ethiopia. Int J Sci Nat 2: 692-697.

8. Thrusfield M (2005) Veterinary Epidemiology. 3rd edn, Blackwell Science Ltd., UK, pp: 229-245

9. Hamito D (2009) Estimation of Weight and Age of Sheep and Goats. ESGPIP, Technical Bulletin 23: 8-10.

10. Suiter J (1994) Body condition scoring of sheep and goats. Farmnote, p: 69.

11. Wall R, Shearer D (1997) Veterinary Entomology. 1st edn, Chapman and Hall, UK, pp: 1-438.

12. Urquhart GM, Armour J, Duncan JL, Dunn AM, Jennings FW (1996) Veterinary Parasitology. 2nd edn., Blackwell Science Ltd., UK, pp: 141-205.

13. Mariam SW (2011) Impact of ectoparasite control campaign on quality of processed skins in tanneries of the Amhara Regional Government: a rapid assessment. Ethiopian Veterinary Journal 15: 103-115.

14. Tadesse A, Fentaw E, Mekbib B, Rahmeto A, Mekuria S, et al. (2011) Study on the prevalence of ectoparasite infestation of ruminanats in and around Kombolcha and damage to fresh goat pelts and wet blue (pickled) skin at Kombolch Tannary, Northestern Ethiopia. Ethiop Vet J 15: 87-101.

15. Sertse DF (2004) Investigation on Ectoparasites of Small ruminants in Selected Sites of Amhara Regional State and their Impact on the Tanning industry. MSc Thesis, Faculty of Veterinary Medicine, Addis Ababa University, DebreZeit, Ethiopia, pp: 40-47.

16. Kebede N, Fetene T (2012) Population dynamics of cattle ectoparasites in Western Amhara National Regional State, Ethiopia. Journal of Veterinary Medicine and Animal Health 4: 22-26.

17. Yacob TH, Yalew AT, Dinka AA (2008) Ectoparasite Prevalence's in Sheep and in Goats in and around Wolaita soddo. South Ethiopia Revue Med Vet 159 450-454.

18. Colwel DD, Bill Clymer B, Booker WC, Guichon TP, Jim KG, et al. (2001) Prevalence of sucking and chewing lice on cattle entering feedlots in southern Alberta. Can Vet J 42: 281-285

19. James PJ, Garrett JA, Moon RD (2002) Sensitivity of two stage sampling to detect sheep biting lice (Bovicola ovis) in infested flocks. Veterinary Parasitology 103: $157-166$.

20. James PJ (1999) Do sheep regulate the size of their mallophagan louse populations. International Journal for Parasitology 29: 869-875.

21. Wilkinson FC, de Chaneet GC, Beetson BR (1982) Growth of populations of lice, Damalinia ovis, on Sheep and their effects on Production and Processing Performance of wool. Veterinary Parasitology 9: 243-252.

22. Niven DR, Pritchard DA (1985) Effects of control of the sheep body louse (Damalinia ovis) on wool production and quality. Australian Journal of Experimental Agriculture 25: 27-31.
Citation: Eticha E, Lemma D, Abera B, Selemon H (2017) Prevalence and Associated Risk Factors to Lice Infestation in Sheep of Arsi High Land Oromiya Regional State, Ethiopia. J Vet Sci Technol 8: 425. doi: 10.4172/21577579.1000425
OMICS International: Open Access Publication Benefits \& Features

\section{Unique features:}

Increased global visibility of articles through worldwide distribution and indexing

- Showcasing recent research output in a timely and updated manner

Special issues on the current trends of scientific research

Special features:

- $700+$ Open Access Journals

$50,000+$ Editorial team

Rapid review process

- Quality and quick editorial, review and publication processing

- Indexing at major indexing services

- Sharing Option: Social Networking Enabled

- Authors, Reviewers and Editors rewarded with online Scientific Credits

- Befter discount for your subsequent articles

Submit your manuscript at: www.omicsonline.org/submission 